\title{
Fragmented dry grasslands preserve unique components of plant species and phylogenetic diversity in agricultural landscapes
}

\author{
Balázs Deák ${ }^{1}$ (D) Zoltán Rádai $^{1}$ (D) Katalin Lukács $^{1} \cdot$ \\ András Kelemen ${ }^{1}$ (D) - Réka Kiss ${ }^{1}$ (D) Zoltán Bátori $^{2}$ (D) \\ Péter János Kiss ${ }^{2} \cdot$ Orsolya Valkó $^{1}$ (D)
}

Received: 8 April 2020 / Revised: 3 October 2020 / Accepted: 9 October 2020 /

Published online: 17 October 2020

(C) The Author(s) 2020

\begin{abstract}
In intensively used landscapes biodiversity is often restricted to fragmented habitats. Exploring the biodiversity potential of habitat fragments is essential in order to reveal their complementary role in maintaining landscape-scale biodiversity. We investigated the conservation potential of dry grassland fragments in the Great Hungarian Plain, i.e. patchlike habitats on ancient burial mounds and linear-shaped habitats in verges, and compared them to continuous grasslands. We focused on plant taxonomic diversity, species richness of specialists, generalists and weeds, and the phylogenetic diversity conserved in the habitats. Verges meshing the landscape are characterised by a small core area and high level of disturbance. Their species pool was more similar to grasslands than mounds due to the lack of dispersal limitations. They held high species richness of weeds and generalists and only few specialists. Verges preserved only a small proportion of the evolutionary history of specialists, which were evenly distributed between the clades. Isolated mounds are characterised by a small area, a high level of environmental heterogeneity, and a low level of disturbance. Steep slopes of species accumulation curves suggest that high environmental heterogeneity likely contributes to the high species richness of specialists on mounds. Mounds preserved the same amount of phylogenetic diversity represented by the branch-lengths as grasslands. Abundance-weighted evolutionary distinctiveness of specialists was more clustered in these habitats due to the special habitat conditions. For the protection of specialists in transformed landscapes it is essential to focus efforts on preserving both patch-like and linear grassland fragments containing additional components of biodiversity.
\end{abstract}

Keywords Habitat island · Steppe $\cdot$ Verge $\cdot$ Plant biodiversity $\cdot$ Grassland specialist plants · Linear landscape element

Communicated by Daniel Sanchez Mata.

Electronic supplementary material The online version of this article (https://doi.org/10.1007/s10531-02002066-7) contains supplementary material, which is available to authorized users. 


\section{Introduction}

Dry grasslands are amongst the most endangered habitats of Europe, due to the large-scale habitat loss and landscape-level fragmentation of grassland habitats (Fletcher et al. 2018). The expansion of agricultural fields and the exponential spread of urban infrastructure (such as roads, canals and settlements) has led to the irreversible loss of many grassland habitats (Deák et al. 2016; Lindborg et al. 2014). As a result, in intensively managed landscapes elements of grassland biodiversity have often been able to survive in small fragments that were not suitable for agriculture or for infrastructural developments (Bhagwat and Rutte 2006; Deák et al. 2020; Löki et al. 2019; Molnár et al. 2017). These fragments often harbour populations of grassland specialist plants, act as an integral element of the semi-natural habitat network, and have a considerable role in maintaining landscape-scale diversity. Nevertheless, they are often considered to be of lower conservation priority compared to continuous grassland stands, and do not receive any legal protection (Lindborg et al. 2014; Deák et al. 2020). Grassland fragments, either of primary (i.e. remnants of a large pristine habitat) or secondary origin (i.e. old recovered grasslands preserving a considerable proportion of the habitat specific species pool), often exist as habitat islands, such as rocky outcrops, midfield islets, ancient burial mounds and cemeteries. Grassland fragments can also be found on linear landscape elements such as road verges, field margins and river embankments (Bátori et al. 2016; Dembicz et al. 2018; Löki et al. 2019). A common attribute of these fragmented habitats is the presence of an unfriendly matrix around them, which is generally represented by agricultural fields or urban areas. Due to their small size, the management of these habitats is often not optimal from a conservation point view; they are often abandoned or used in an over-intensified way.

Given the fact that grassland fragments may hold a considerable amount of the habitatspecific species pool in transformed landscapes, one current task of conservation is to evaluate their conservation value, which is greatly determined by the level of both taxonomic diversity (richness of the total species pool and the species groups of specialists, generalists and weeds) and phylogenetic diversity (interspecific evolutionary distances) (Devictor et al. 2010). From a conservation point of view, the most important segments of the plant species pool are represented by the habitat specialist species (i.e. species confined exclusively to grasslands); either their presence or absence in a certain fragment can be informative for strategic conservation planning (Szava-Kovats et al. 2012). Besides, the species richness of generalists and weeds may also provide important information on the ecological processes related to degradation.

It is widely accepted that phylogenetic diversity is a proper measure for the evaluation of habitat conservation priorities, as it can combine aspects of taxonomic diversity and the total evolutionary history of conservation interest typical of a certain area or habitat type (Devictor et al. 2010). Phylogenetic data derived from undisturbed natural habitats in a favourable conservation status can serve as references for conservation or even for restoration (Barak et al. 2017). Phylogenetic diversity can also be used as a predictor of ecosystem functions and properties since phylogenetic information might provide a proxy for functional trait attributes via phylogenetic niche conservatism (Barak et al. 2017). Therefore, it can help us to better understand the mechanisms affecting grassland communities (Cadotte et al. 2010; Barak et al. 2017).

In fragmented habitats the species richness of specialists, generalists and weeds are influenced by environmental and dispersal filters acting on the local- and landscape-scales. 
According to the classical theory of island biogeography, the richness of specialist species and the available habitat area are positively correlated; thus, habitat area can considerably influence biodiversity patterns in small fragmented habitats (MacArthur and Wilson 1967). However, other habitat-scale factors such as the shape and the environmental heterogeneity of the fragment can considerably modify this pattern (Báldi 2008; Bátori et al. 2017). For instance, a high perimeter-to-area ratio results in the reduction of core areas that act as safe havens for specialists, and thus supports the immigration of generalists (Kuussaari et al. 2009). Environmental heterogeneity (e.g. topographic, climatic or edaphic variables) may increase the number of available micro-sites in grasslands and has the potential to enhance the structural complexity of the resources and limiting factors (Lisetskii et al. 2016; Stein et al. 2014). Thus, grasslands with a high level of environmental heterogeneity are potentially able to sustain a higher level of biodiversity, and as a corollary of this, have the potential to maintain a higher proportion of the landscape-scale species pool compared to homogeneous habitats (Stein et al. 2014). Landscape composition, and especially the level of connectivity with other grassland habitats, act as crucial drivers of the meta-population dynamics of specialist and generalist species (Deák et al. 2018; Fletcher et al. 2018).

To reveal the relative importance of habitat size, habitat shape, environmental heterogeneity and habitat connectivity in driving the species composition and diversity of continuous grasslands and fragmented grasslands (i.e. patch-like and linear-shaped grasslands), we used a comparative approach. We investigated three grassland types typical of lowland agricultural landscapes in Central and Eastern Europe: continuous grasslands, patch-like grassland fragments on kurgans (ancient earthen burial mounds) and linearshaped grassland fragments (verges).

Patch-like grassland fragments such as midfield islets and rocky outcrops are typical elements of agricultural landscapes in Europe. Despite their small size, small core area and isolated state, they often act as important refuges for grassland specialists (Lindborg et al. 2014). In our study we used kurgans — built in the Eneolithic and Iron Age-as model habitats for patch-like grassland fragments, as they are widespread elements of the continental parts of Eurasia (their estimated number is more than half a million), preserving grassland patches in agricultural landscapes (Deák et al. 2016; Sudnik-Wójcikowska et al. 2011).

Verges are linear landscape elements with a high perimeter-to-area ratio but without a notable core area. As verges are often positioned along roads, they are affected by different types of disturbances related to the traffic and maintenance of the roads (van der Ree et al. 2015), such as pollution, application of herbicides and improper management (i.e. too frequent mowing). Given the fact that verges are usually surrounded by hostile environments (e.g. roads and agricultural fields) and frequently experience high disturbance levels due to stochastic events, they generally hold relatively young (a few hundred years or decades old) and disturbed secondary grasslands. However, given their linear shape, they may act as corridors for the dispersal of several plant species (both native and non-native).

We compared the taxonomic diversity, the species richness of species groups (specialists, generalists and weeds) and the phylogenetic diversity conserved by these habitats. We asked the following questions: (i) What are the differences in the species composition of continuous and fragmented grasslands? (ii) Do the taxonomic diversity and species accumulation curves of specialist, generalist and weed species differ in the grassland types studied? (iii) Is there any difference in between-habitat interspecific evolutionary distances represented by phylogenetic diversity? (iv) Which are the characteristic species of the continuous and fragmented grasslands; and how do these species contribute to the maintenance of phylogenetic diversity? 


\section{Materials and methods}

\section{Study area}

The study area is situated in the Hungarian Great Plain, covering approximately $5800 \mathrm{~km}^{2}$. The Hungarian Great Plain is a typical lowland agricultural landscape which represents well the land use changes and agricultural intensification processes relevant for many European landscapes. The area has a continental climate with a mean annual temperature of $10.4{ }^{\circ} \mathrm{C}$ and a mean annual precipitation of $538 \mathrm{~mm}$ (Fick and Hijmans 2017). The historical landscape was characterised by loess and alkaline grasslands and wetlands, but due to agricultural intensification since the eighteenth century there have been considerable losses in the area of grasslands. Loess grasslands (Salvio nemorosae-Festucetum rupicolae) on nutrient-rich chernozem soils have suffered the most severe decline due to ploughing. As a result, their area has decreased by $90 \%$ in past decades (Biró et al. 2018). They are species-rich dry grasslands included in the Natura 2000 network as habitats of European importance (6250 Pannonic loess steppic grasslands) (Council Directive 92/43/ EEC). The dominant graminoid species include Festuca rupicola, Bromus inermis, Carex praecox, Koeleria cristata, Poa angustifolia and Stipa capillata. Loess grasslands usually harbour a high number of forb species, including Achillea collina, Agrimonia eupatoria, Filipendula vulgaris, Fragaria viridis, Phlomis tuberosa, Salvia austriaca, S. nemorosa, Thymus glabrescens and Verbascum phoeniceum.

We studied loess grasslands, which typically occur under three circumstances in our study area: (i) continuous (pristine) grasslands, (ii) patch-like fragmented (secondary) grasslands on kurgans and (iii) linear-shaped fragmented (secondary) grasslands in roadside verges. For information on the size of the study sites and their distance from the nearest continuous grassland stand (in the case of kurgans and verges), please see Online Resource 1.

Continuous grasslands with a mean area of 272.1 ha $(\mathrm{SD}=364.4)$ typically occur on loess plateaus. They are traditionally managed by cattle grazing and in some cases by annual mowing. This traditional extensive management system is still maintained in the sampled continuous grassland stands. Since they are often characterised by a large core area, they are less affected by the negative effects (e.g. chemical infiltration and seed rain of weeds) originating from the neighbouring matrix (Biró et al. 2018).

Patch-like secondary grasslands on kurgans are generally surrounded by ploughlands and forest plantations. Before the huge loss and fragmentation of grassland habitats in the eighteenth century, they were also managed by grazing as they were integral elements of large continuous grassland stands. After their isolation due to the reduction in continuous grassland stands, they became abandoned, since their small size and difficult accessibility made the management of these grassland patches challenging and less cost-efficient. The mean size of the kurgans studied was uniform, with an area of 0.2 ha $(\mathrm{SD}=0.1)$. The kurgans surveyed were isolated, with a mean distance from the nearest continuous grassland stand of $716.4 \mathrm{~m}$ (SD = 700.6). Due to their special dome shape, kurgans contain several contrasting microhabitats within a small area (Lisetskii et al. 2016). Their slopes with different inclinations are characterised by different microclimate and soil conditions leading to a high level of microhabitat diversity (Dembicz et al. 2018; Lisetskii et al. 2016).

Roadside verges also harbour secondary loess grasslands, which are generally managed by mowing at least twice per year. Estimation of their age is more challenging compared to kurgans (which are marked even on the Military Surveys of the Habsburg Empire from the 
eighteenth century), but they likely have existed for centuries as remnants of the continuous grasslands which were formerly present. The mean length of the studied verges was $839.3 \mathrm{~m}(\mathrm{SD}=395.9)$ and their average distance from continuous grasslands was $185.9 \mathrm{~m}$ $(\mathrm{SD}=206.9)$, but in some cases they had close contact with them at some points.

\section{Vegetation sampling}

We selected eight sites of the three habitat types for vegetation sampling, i.e. pristine continuous loess grasslands, loess grassland fragments on kurgans and roadside verges, referred to hereafter as 'continuous grasslands', 'kurgans' and 'verges'. All the 24 sites selected were typical representatives of the loess grasslands in the study area. We selected sites not affected by woody encroachment (although in some sites there were saplings of some woody species). We recorded the percentage cover of each vascular plant species in 25 plots of $1 \mathrm{~m}^{2}$ in each site in July 2019. In total we sampled 600 plots ( 3 habitats $\times 8$ sites $\times 25$ plots). In order to ensure that the sampling effort was the same in all habitat types we used a uniform sampling method, and we arranged our plots randomly within an area of 0.1 hectare fitted to the area of the smallest kurgan. In the case of kurgans the 25 plots were placed in such a way as to represent the environmental heterogeneity of the kurgans: we surveyed all kurgan microhabitats (north-, east-, south- and west-facing slopes and the top) by placing five random plots in each microhabitat (5 kurgan microhabitats $\times 5$ plots).

\section{Statistical analysis}

Species were assigned to three species groups relevant for conservation: specialists, generalists and weeds. Species richness and cover of specialist species provide information about the conservation value preserved by the grasslands. Proportions of weeds indicate unfavourable processes in the grasslands studied (such as improper management, disturbance and plant invasions). Generalist species are important components of grassland habitats that contribute to the total species richness but do not directly indicate degradation or favourable conservation status. Therefore, we treated them as a separate group. When generalist species are present in high numbers and abundance, they can competitively exclude both specialists and weeds; therefore, they can indirectly affect the conservation status of the grasslands. Based on this classification, the presence of weeds indicates acute degradation processes that should be dealt with urgently by conservation managers. However, moderate species richness and abundance of generalists might not necessarily mean a drastic decline in the conservation value of the grasslands, since many of them are also integral parts of grassland ecosystems with good conservation values.

Specialist species were classified according to their phytosociological affiliation to the Festuco-Brometea phytosociological class (Borhidi 1995). Weeds were classified based on their social behaviour types: weed, ruderal competitor and adventive competitor species were classified as weeds (Borhidi 1995). All other species were considered as generalists. All statistical analyses were carried out in the $\mathrm{R}$ environment for statistical computing (ver. 3.6.1; R Core Team 2019). To test whether there are general differences in species composition between the three habitat types we applied permutational multivariate analysis of variance (PERMANOVA; R-package "vegan”, Oksanen et al. 2019). Visualization of species composition was done using the Barnes-Hut implementation of t-distributed stochastic neighbour embedding (t-SNE: Van der Maaten 2014; R-package "Rtsne": 
Krijthe 2015), in which a species abundance matrix was used, and dimensionality was set to 2. We preferred t-SNE over principal component analysis, because with the former we could explicitly specify the dimensions onto which the raw data should be transformed, whereas this is not the case with principal component analysis.

When comparing total species richness (i.e. total number of species per sampling plot) and species richness of specialists, generalists and weeds between habitat types, generalized linear mixed-effects models (GLMM; R-packages "lme4" and "lmerTest": Bates et al. 2015; Kuznetsova et al. 2017) were fitted with Poisson error distribution, in which total species richness and richness of specialists, generalists and weeds were the dependent variables, habitat type (a factor with three levels: continuous grassland, kurgan and verge) was the fixed predictor, and sampling site ID was used as random factor. We also fitted Gaussian linear mixed-effects models (LMM) on the Shannon diversity of the total species pool per habitat type; similarly to the Poisson GLMMs, habitat type was the fixed predictor variable, and sample site ID was used as random factor. From all models, statistical significances of pairwise differences between habitat types were acquired by computing estimated marginal means (EMM), and regression slope estimates for habitat types were acquired by computing estimated marginal mean linear trends (EMT; R-package "emmeans": Lenth 2019). P-value adjustments for multiple comparisons within models were done using Tukey's method (Lenth 2019).

By increasing the variability of available niches, the environmental heterogeneity of a certain habitat can considerably influence the patchiness, and thus the species richness of the vegetation. For estimating this patchiness within the three habitat types, we used species accumulation curves. Species accumulation curves were estimated for total species richness and for species groups, by using Gaussian LMMs. Since all sampling plots represented the same area sizes of sampling, we used sampling plot numbers (i.e. sampling intensity) for the species accumulation analysis. We randomly drew 1, 2, ., 25 samples from the species richness data, repeated 50 times from each sampling site and for each sampling size; by doing so we obtained species richness data for different sampling sizes (from 1 to 25). In the models the response variable was the power function of species richness using $\log$ S-space formula (Dengler et al. 2020), while the fixed predictor was the sample size (ranging from 1 to 25), the habitat type, and the interaction between the two predictors. Sampling plot ID was used as random factor, and sampling plot-level variances in slopes were also controlled for (i.e. we utilized a random intercept and slope model).

To identify indicator species for the habitat types we used multi-level pattern analysis with the R-package "indicspecies" (Cáceres and Legendre 2009), with 1000 permutations. In the analysis, group combinations were included in order to identify species that might be indicators for a combination of two habitat types, which could indicate wider niche breadths for certain species (Cáceres et al. 2010). We also quantified the proportion of plots at a certain habitat, where at least one habitat type-specific indicator species was present (referred to as indicator frequency).

For tests of habitat type differences in phylogenetic diversity (PD) we used the megaphylogeny of plants by Durka and Michalski (2012) updated by Qian and Jin (2016). Three species were excluded from the PD analyses due to a lack of phylogenetic information on them (namely: Equisetum arvense, E. ramosissimum, and Lepidium draba). For estimating the differences in the quantity of phylogenetic differences conserved by the three habitat types we used PD 'richness metrics' suggested by Tucker et al. (2017). We used community PD (cPD) expressing the amount of evolutionary history across species, and abundance-weighted evolutionary distinctiveness (AED) expressing the abundance weighted phylogenetic information on present species in a given community. These indices 
were used as response variables in separate Gaussian LMM models, with habitat type as the fixed predictor, and sampling plot ID as the random factor. In addition, phylogenetic diversity models were re-fitted on a subset of data, using only specialist species in the analysis, as these species are of special conservation interest. Notably, AED can be calculated separately for species within a community, rendering it possible to assess the relative importance of species in terms of their contribution to the phylogenetic diversity of the given community. Hence, one can assess for each monitored species what the average species-AED is in the different habitat types. We utilized species-AED to see whether species that were predicted to be indicators for a given habitat type also had the highest species-AED values in the given habitat types, by checking the overlap between the indicator and highest-species-AED species.

\section{Results}

In total we recorded 229 vascular plant species in the study sites: 135 species occurred in the continuous grasslands, 145 on the kurgans and 136 in the verges. There were a total of 55 specialist, 111 generalist and 63 weed species in the study sites. We recorded a total of 33, 41 and 27 specialist species in continuous grasslands, kurgans and verges, respectively. 7 specialist species were present only in continuous grasslands, 17 only on kurgans and 4 only in verges. There were 72 generalist species in continuous grasslands, 64 on kurgans and 65 in verges. 12 generalist species occurred only in continuous grasslands, 19 only on kurgans and 19 in verges. A total of 30 weed species were found in continuous grasslands, 40 on kurgans and 44 in verges. 1 weed species was present only in continuous grasslands, 14 only on kurgans and 14 in verges.

\section{Species composition}

Both the results of the t-SNE (Fig. 1) and the PERMANOVA analyses (sum of squares $\left.=14.802 ; \mathrm{F}=21.541 ; \mathrm{R}^{2}=0.067 ; P=0.001\right)$ revealed that whilst the species composition of verges was similar to the continuous grasslands, kurgans held a somewhat different species composition which was more homogeneous compared to the composition of the other two habitat types.

\section{Shannon diversity and species richness}

Shannon diversity calculated for the total species pool was significantly lower on kurgans than in continuous grasslands and verges. Total species richness on kurgans was significantly lower than in verges, but did not differ from continuous grasslands, nor was there a significant difference between verges and continuous grasslands. Habitat type differences were somewhat more nuanced when tested separately for species groups (Fig. 2, Online Resource 2). The species richness of specialists was the lowest in verges, while it did not significantly differ between continuous grasslands and kurgans. For generalist species, the lowest species richness was observed on kurgans, whereas continuous grasslands and verges did not differ. The species richness of weeds was the lowest in continuous grasslands, but there was no difference between kurgans and verges. 
Fig. 1 Species composition of the three habitat types displayed by t-distributed stochastic neighbour embedding ( $\mathrm{t}-\mathrm{SNE}$ )
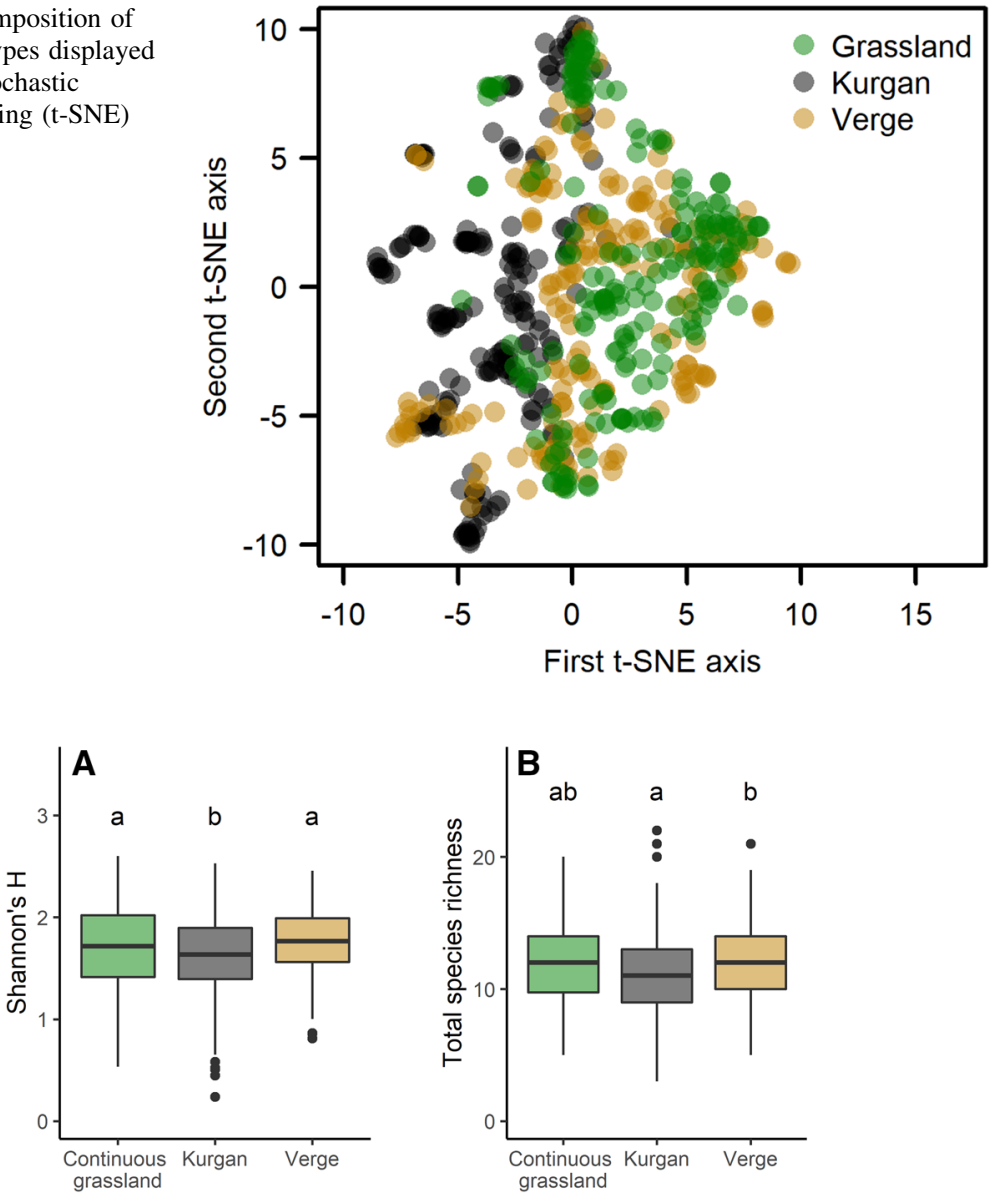
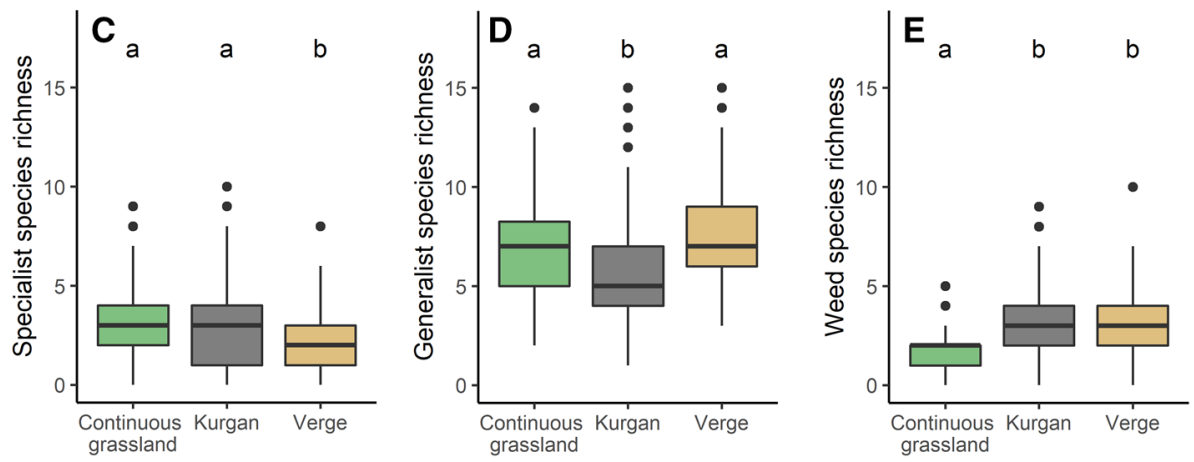

Fig. 2 Shannon diversity (A), total species richness (B) and species richness of specialists (C), generalists (D) and weeds (E) in the three habitat types (continuous grassland, kurgan, verge), and the results of the LMM (for Shannon's diversity) and the GLMMs (for species richness). Superscript letters denote significant differences between groups $(P \leq 0.05$ after Tukey's test) 


\section{Indicator species}

Multilevel pattern analysis identified 135 species as significant indicator species of a habitat type, or of a combination of two habitat types (Online Resource 3). From these, 20, 43, and 33 species were found to be exclusive indicators of continuous grasslands, kurgans and verges, respectively. Besides, 10 indicator species were found for the continuous grassland-kurgan combination, 18 species for the continuous grassland-verge combination, and 11 species for the kurgan-verge combination. The highest number of specialist indicator species was observed on kurgans, but kurgans also harboured the most weed indicator species, whereas the highest number of generalist indicator species was recorded in verges (Online Resource 4). Indicator frequency (i.e. the proportion of plots where particular indicator species were present) was $80 \%, 99 \%$, and $91 \%$ for continuous grasslands, kurgans, and verges, respectively. In the case of habitat type combinations, indicator frequency was estimated to be $85.5 \%, 99.5 \%$, and $93 \%$ in continuous grassland-kurgan, continuous grassland-verge, and kurgan-verge combinations, respectively.

\section{Species accumulation curves}

Species accumulation curves calculated for the total species richness were positive (species richness increases with an increasing number of samples) and significant for continuous grasslands $(\mathrm{EMT}=0.377, \mathrm{SE}=0.014, \mathrm{z}$-ratio $=27.52, \mathrm{P}<0.001)$, kurgans $(\mathrm{EMT}=$ $0.402, \mathrm{SE}=0.014, \mathrm{z}$-ratio $=29.34, \mathrm{P}<0.001)$, and verges $(\mathrm{EMT}=0.375, \mathrm{SE}=0.014$, $\mathrm{z}$-ratio $=27.37, \mathrm{P}<0.001)$. In the LMM with all species the accumulation curve was steeper in kurgans than in continuous grasslands and verges, while accumulation curves did not significantly differ between the latter two (Fig. 3, Online Resource 5). Within specialists, the accumulation curve was the steepest in kurgans and continuous grasslands, and was the shallowest in verges. No significant difference was found in the accumulation curve between kurgans and continuous grasslands. Considering generalists, kurgans had the steepest accumulation curve, while continuous grasslands and verges had a significantly shallower curve and they did not differ significantly. For weeds, kurgans showed the steepest species accumulation curve, whereas continuous grasslands showed the shallowest, and all habitat types were significantly different from one another in their species accumulation rates.

\section{Phylogenetic diversity}

Community PD values calculated for the total species pool were significantly smaller for kurgans than for continuous grasslands, while kurgans and continuous grasslands did not differ from verges (Fig. 4, Online Resource 6). Habitat types did not differ in their AED values. When only specialist species were considered, we found significant differences among habitats both in the case of $\mathrm{cPD}$ and AED. We found that the $\mathrm{cPD}$ values were lower for verges than for continuous grasslands. AED was significantly lower in verges than in the other two habitats.

The joint assessment of indicator species analysis and species-AED showed that there were 17 continuous grassland, 36 kurgan and 29 verge indicator species which also showed the highest species-AED values in the given habitat types. In other words, these indicator species contributed substantially to the (abundance-weighted) phylogenetic diversity of their habitats. When only specialist species were considered, the number of predicted 

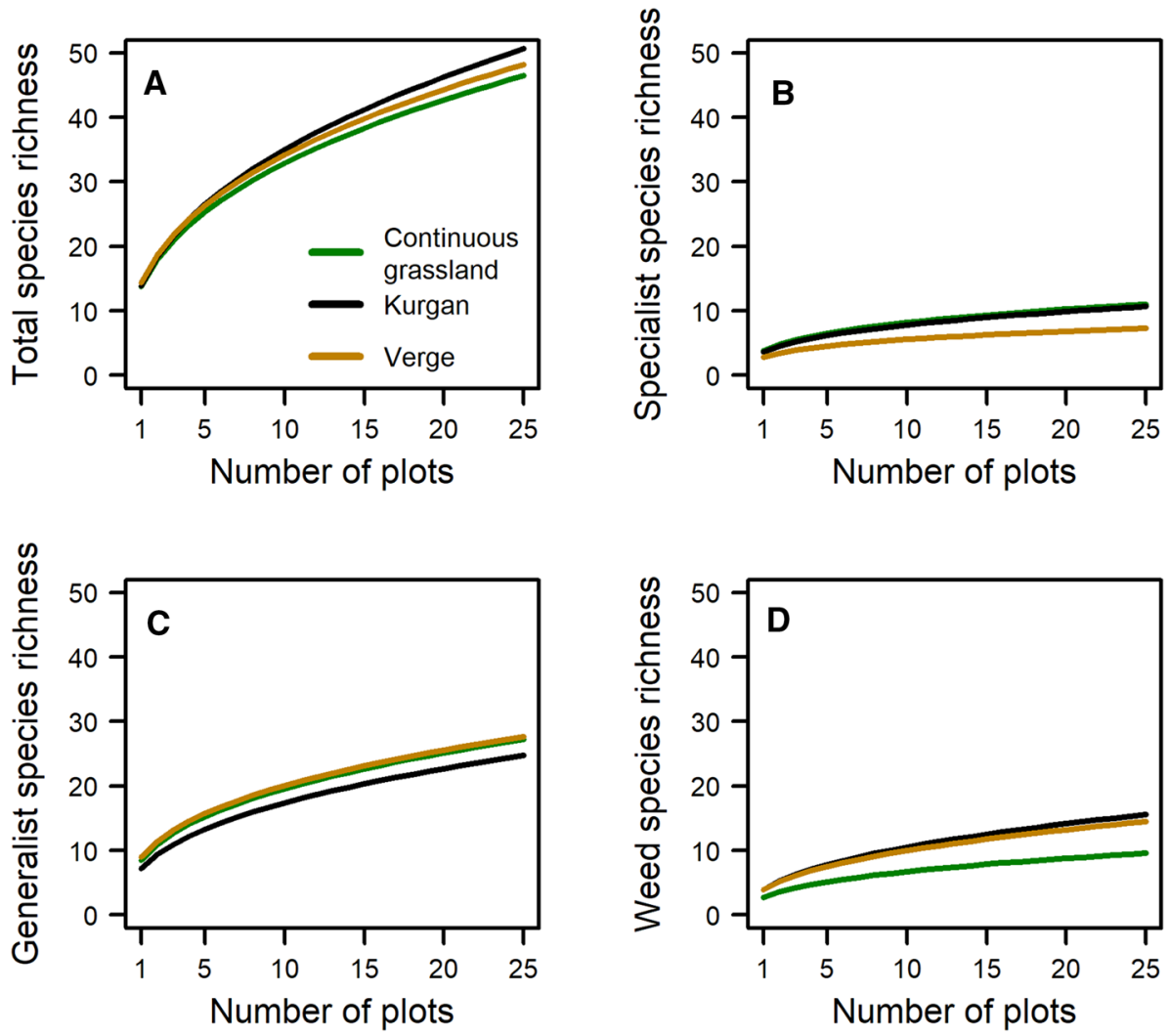

Fig. 3 Species accumulation curves displayed for all species (A), specialists (B), generalists (C) and weeds (D) in the three habitat types

indicator species with high species-AED values was 8, 11 and 6 in continuous grasslands, kurgans, and verges, respectively (Fig. 5).

\section{Discussion}

\section{Species composition}

We found that continuous grasslands and verges harboured a similar species pool (Fig. 1). The reason for this is twofold. As verges were formed during the past centuries in parallel with the increasing agricultural activities, they were able to preserve a large subset of the regional species pool similar to that harboured by the continuous grasslands. Similar species pools also suggest that verges and continuous grasslands might have a functional spatial connection even in fragmented landscapes (i.e. at certain locations they have connection points), allowing the dispersal of species between the two habitat types. This connection is supported by the linear structure of the verges; they mesh the landscape and therefore they provide corridors for the dispersion of plants. Given the fact that verges are in close contact with roads, dispersal of plants is also supported by the various means of transportation and mowing machines used for cutting the verges (Fekete et al. 2018). In 

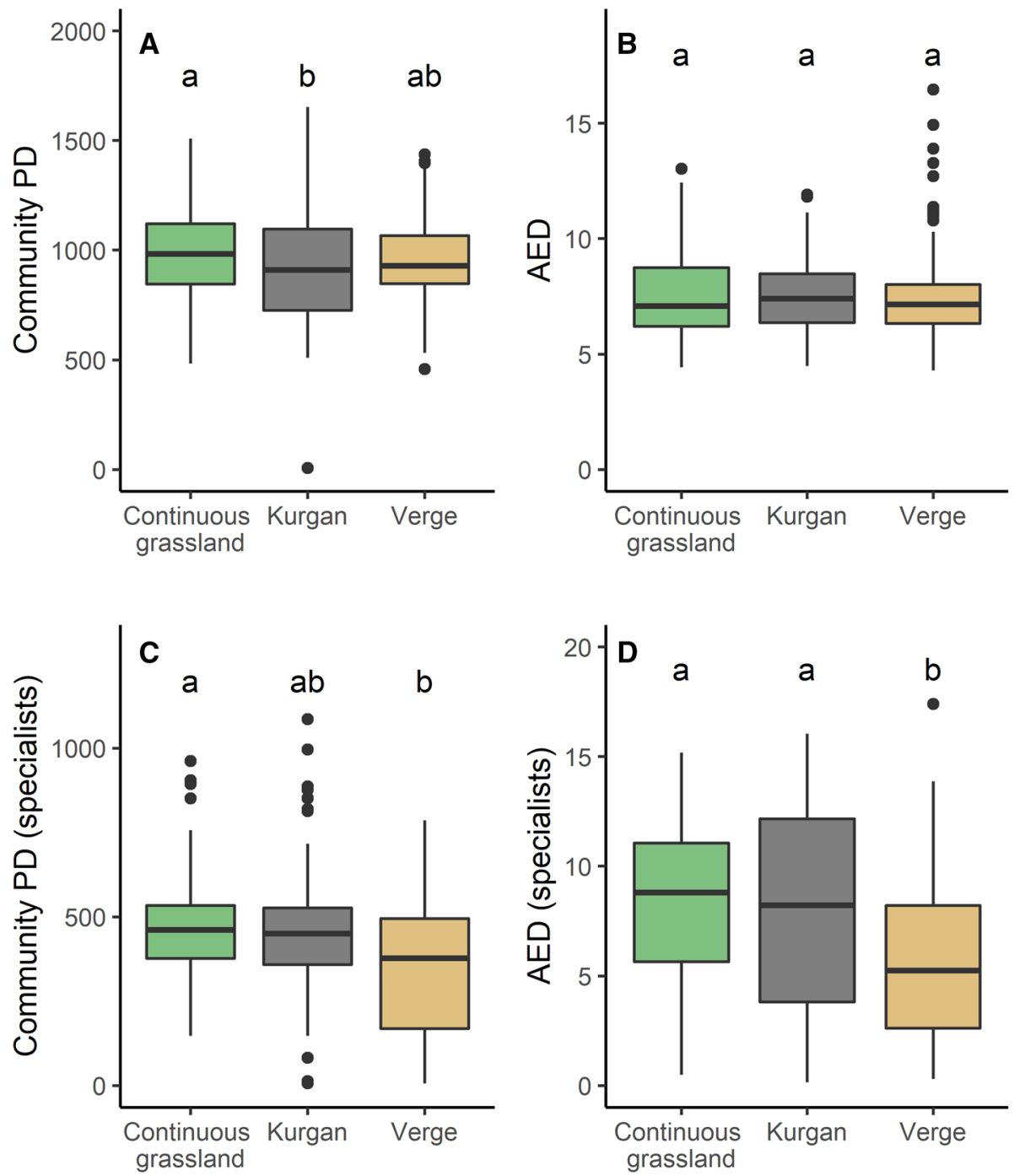

Fig. 4 Community phylogenetic diversity (cPD) and abundance-weighted evolutionary distinctiveness (AED) calculated for all species $(\mathbf{a}, \mathbf{b})$ and specialists $(\mathbf{c}, \mathbf{d})$ in the three habitat types (continuous grassland, kurgan and verge). Superscript letters denote significant differences between groups (GLMM; $P \leq 0.05$ after Tukey's test)

addition, in agricultural landscapes human vectors can transport grassland specialist species on the clothes of field workers and on agricultural machinery (Auffret and Cousins 2013). However, humans can also act as dispersal vectors for invasive and weed species (Valkó et al. 2020). By decreasing dispersal limitations, all the above processes can considerably increase the similarity of the species composition between continuous grasslands and verges.

As shown by the results of the t-SNE and the PERMANOVA analyses, the species composition of the vegetation on the kurgans differed considerably from that of the 


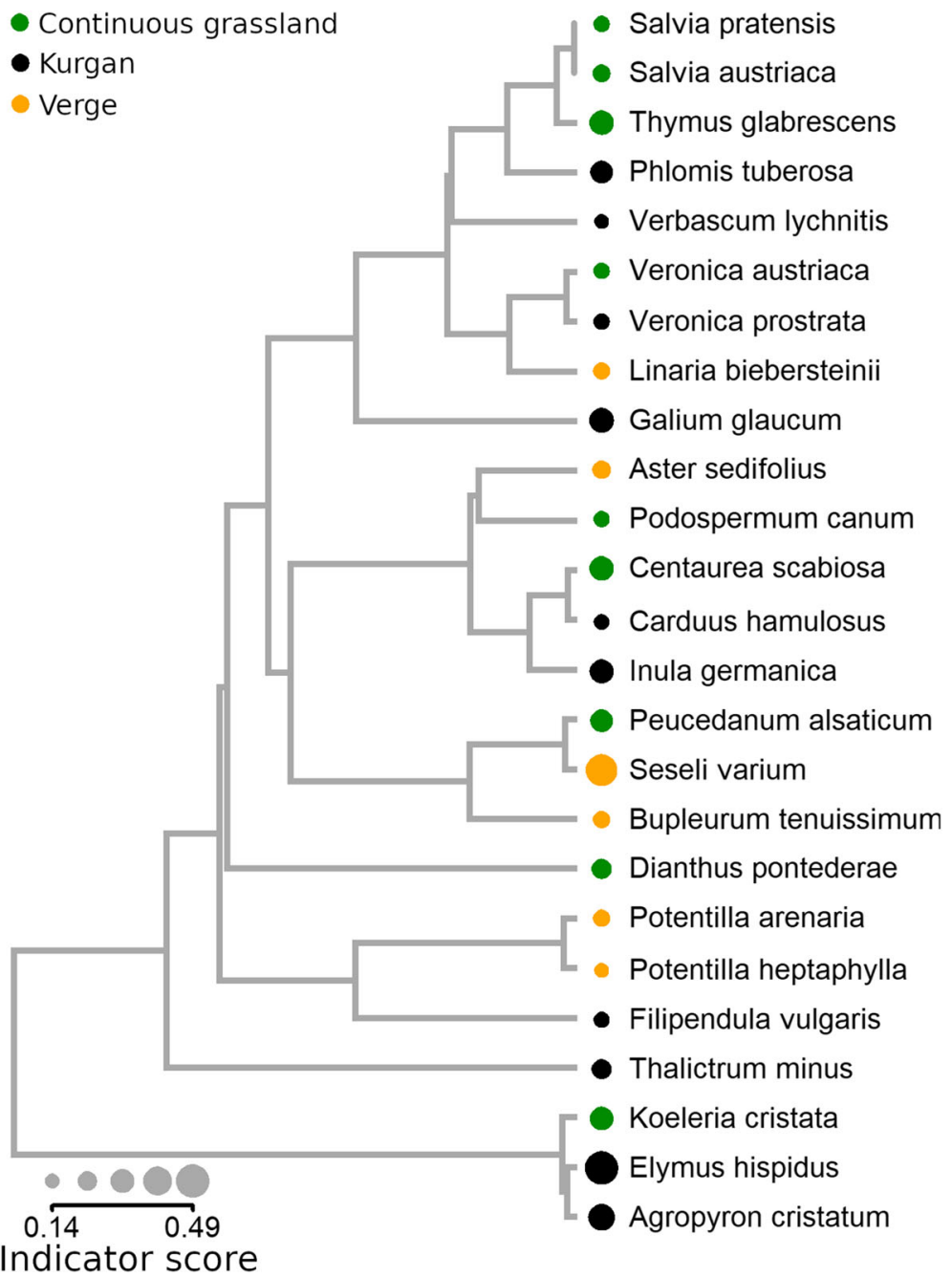

Fig. 5 Linking abundance-weighted evolutionary distinctiveness to indicator scores using phylogenetic information. Specialist species that were significant indicators of a particular habitat type are displayed on the figure

vegetation of the continuous grasslands and verges. This might be due to their ancient origin; secondary grasslands on kurgans were formed millennia ago, before the large-scale landscape transformations. After the emergence of the kurgans they were likely occupied by the species that were present in the historical species pool since they were surrounded by grassland habitats and even the soil used for their construction contained the propagules of grassland species (Lisetskii et al. 2016). However, the special environmental conditions provided by the shape of the kurgans should have acted as an environmental filter for plant establishment, allowing only a certain subset of species to establish on the kurgans after their construction (Lisetskii et al. 2016; Szava-Kovats et al. 2012). This compositional difference was conserved by the special hill shape of the kurgans in subsequent millennia, 
both by environmental filtering, and by preventing certain human disturbances such as ploughing or construction.

\section{Shannon diversity and species richness}

Differences in the Shannon diversity and richness of the studied species groups among the three habitat types can be explained by the marked differences in their origin, the shape and size of the habitats, the applied management regimes, and the level of habitat heterogeneity typical of them. Despite their small area, lack of management and the neighbouring unfavourable landscape matrix (i.e. ploughlands), the millennia-old grassland islands maintained by kurgans were able to preserve a high number of specialists. Patch-like grassland fragments embedded in agricultural fields are generally characterised by drier soil conditions than the neighbouring areas, and this provides a favourable habitat for stress-tolerant dry grassland specialists even without management (Lindborg et al. 2014). In the case of kurgans this effect is enhanced by the special hill shape, which results in an enhanced flow of precipitation on the slopes and an increased distance between the topsoil layer and the groundwater (Lisetskii et al. 2016). Due to their steep slopes human disturbances (e.g. ploughing) have been suppressed on kurgans, which has further increased the chance for the maintenance of specialists (Deák et al. 2016). Furthermore, despite their small size the increased level of microhabitat diversity preserved on the heterogeneous surface of kurgans allows the co-existence of specialist species with slightly different habitat requirements (Lisetskii et al. 2016; Deák et al. 2016). In contrast, the species richness of generalists was low on kurgans. The main reason for this is that generalists typically occur under less stressful habitat conditions than those provided by kurgans. However, we found high species richness and cover of weeds on kurgans, indicating the vulnerability of these grassland fragments to the mass effect of incoming seed rain from the neighbouring ploughlands (Deák et al. 2018).

Due to the small or missing core area, specialists in the verges are especially exposed to the negative effects (e.g. chemical load, seed rain of weeds and soil disturbances) originating from the neighbouring matrix (roads and ploughlands) and to local disturbances (trampling, frequent mowing and application of pesticides), leading to the stochastic extinction of specialists from certain habitat patches (Tikka et al. 2000). In contrast with kurgans and continuous grasslands, the small level of environmental heterogeneity in verges cannot counterbalance these negative changes (Tikka et al. 2000). Due to the dense seed bank, high dispersal ability and high regeneration potential of weeds and generalists, they have a higher chance to re-establish in the disturbed patches than specialists; thus, in the long term, their populations dominate these habitats (Cousins 2006). Even though linear landscape elements have the potential to act as green corridors for grassland specialists given their connections to continuous grasslands (Bátori et al. 2016, 2020), they may also provide corridors for generalist and weed species, especially in transformed landscapes (Fekete et al. 2018), where their spread is enhanced by transportation and by mowing machinery (Tikka et al. 2000).

\section{Species accumulation curves}

Despite their small size and isolated state, the steepest accumulation curves calculated for the total species pool were found on kurgans, which might be the result of the high topographic heterogeneity and microhabitat diversity (that are also responsible for their 
high species richness) (Fig. 3). As was found by Polyakova et al. (2016) in steppe habitats and Filibeck et al. (2019) in limestone grasslands, variability in the micro-relief and unevenness of the surface support the existence of numerous microhabitats within short distances, providing various niche spaces available for several taxa. These adjacent microhabitats are characterised by different species pools; thus, spatial variability of species combinations increases considerably even within small spatial scales of a few metres.

As was found in the case of midfield islets (Lindborg et al. 2014) and coastal grasslands (Dupre and Diekmann 2001), abandonment did not flatten the accumulation curve, in fact it even made it steeper. The reason for this pattern is likely the presence of harsh environmental conditions, such as drought stress in the case of midfield islets and kurgans and salt stress in the case of coastal habitats, preventing the monodominance of a few strong competitors and providing patchy species occurrence patterns in the community. Regarding the total species pool, the steepness of the curves was similar in continuous grasslands and verges; however, mechanisms sustaining these patterns were likely different. In continuous grasslands the extensive and often selective cattle grazing and trampling suppress the abundant competitor species, and allow the establishment of subordinate species with poorer competitive abilities (Polyakova et al. 2016). In this way, grazing enhances the patchiness of the vegetation, and thus the steepness of the species accumulation curve. In verges, the high level of disturbance resulting in open patches might be the main factor that maintains a steepness comparable to continuous grasslands.

On the level of specialist species, kurgans and continuous grasslands were characterised by a similarly high steepness in the accumulation curve, suggesting that the number and spatial variability of species of high conservation importance are the highest in these habitats. In continuous grasslands the traditional method of land use is responsible for this pattern. Probably the most interesting finding of our study is that kurgans-despite their abandonment, small size and isolated state-showed a comparable conservation value to continuous grasslands; because they have preserved a considerable proportion of the historical habitat-specific species pool. The preservation of specialist species is also supported by the harsh environment and their heterogeneous topography. In verges, the accumulation curve was flatter for the specialists due to the high level of disturbance by frequent mowing and trampling, eliminating several disturbance-sensitive species. Another reason for this pattern might be the increased level of nutrients received from the neighbouring agricultural land. As was observed in grasslands in Italy and Germany (Chiarucci et al. 2006), increased nutrient levels might suppress specialists and flatten the species accumulation curves. Although kurgans were characterised by steep accumulation slopes for specialists, they also had the steepest slopes for generalists and weeds, suggesting that these important refuges are highly endangered. The reason for the above patterns is the presence of several disturbed microhabitats (ploughing and chemical infiltration at the foot of the kurgan, the presence of fox burrows, and microsites with high litter accumulation) on the kurgans that can be occupied by generalist and weed species (see also Godó et al. 2018).

\section{Indicator species}

We found several indicator species for the habitat types studied, which may reflect the history, management and landscape context of these habitats. The presence of grazingtolerant specialists (such as Centaurea scabiosa s.l., Thymus glabrescens, Koeleria cristata and Dianthus pontederae) in continuous grasslands indicated the century-long grazing 
management applied. Kurgans were characterised by some tall-growing specialists (e.g. Elymus hispidus, Agropyron cristatum and Thalictrum minus), and some protected species (e.g. Inula germanica, Phlomis tuberosa and Carduus hamulosus) that are usually missing from the continuous grasslands of the region. Although most of these species could have been typical of the continuous grasslands in the past, their populations have almost completely disappeared from the landscape due to agricultural intensification and melioration works (Biró et al. 2018). The presence of these specialists underlines the high conservation importance of kurgans, which often hold the remnant populations of many species that are endangered due to intensive land use (Deák et al. 2020).

The shared indicator species between continuous grasslands and kurgans were mostly specialists (Cruciata pedemontana, Verbascum phoeniceum and Stipa capillata) and generalist species typical to grasslands (Alopecurus pratensis, Veronica verna, Hypericum perforatum and Cerastium semidecandrum) reflecting the common historical species pool. Whilst continuous grasslands held weeds typical of extensive pastures, the abandoned kurgans were characterised by weeds typical of oldfields and ploughlands. The presence of Lepidium draba indicates soil disturbance by foxes, which prefer kurgans embedded in ploughlands for burrowing (Godó et al. 2018). Other arable weeds such as Lathyrus tuberosus, Vicia spp. and Bromus arvensis were likely established on the kurgans from the neighbouring ploughlands and oldfields (Sudnik-Wójcikowska et al. 2011). The invasion of the terrestrial reed (Phragmites communis) indicates the long-term abandonment of the grasslands on kurgans. The unique species composition of kurgans is also indicated by the high (99\%) coverage of indicator species.

Verges harboured many generalist and weed indicator species, reflecting the species pool of the contemporary intensively used landscape. Indicator generalist species of verges (Verbascum chaixii, Equisetum ramosissimum, Bromus commutatus and Silene vulgaris) and shared generalists between continuous grasslands and verges (Festuca rupicola, Achillea collina, Eryngium campestre, Plantago lanceolata, Centaurea pannonica, Agrimonia eupatoria and Knautia arvensis) are adapted to frequent disturbances such as biomass removal and trampling, which are typical in mown verges affected by continuous human presence. Due to the high level and frequency of disturbances, only a few specialist species such as Peucedanum alsaticum and Aster sedifolius could establish in the verges. These species are able to colonize open disturbed soil surfaces due to their good dispersal and establishment ability. Bromus inermis was typical both on kurgans and in verges, as the effective clonal spread of this species is a successful strategy both in disturbed and environmentally heterogeneous habitats (Rosenthal and Lederbogen 2008). The presence of woody indicator species (Rubus caesius and Prunus spinosa) was also typical on the kurgans and in the verges. On kurgans their presence is a consequence of the abandonment, while in verges they are typical because of the high disturbance levels, and their effective dispersal is supported by birds and transportation on the adjacent roads (Suárez-Esteban et al. 2013).

\section{Phylogenetic diversity}

We found that cPD values calculated for the total species pool were lower on kurgans than in continuous grasslands, which might be attributed to the high number of generalist species in continuous grasslands which increased the sum of the branch lengths (Fig. 4). A possible reason for this pattern is that the earliest terrestrial plant species may have been generalists and cosmopolitans (Steemans et al. 2009), which then underwent a rapid 
diversification, and thus are located on different branches of the phylogenetic tree. The high $\mathrm{CPD}$ values calculated for the total species pool in verges might also be attributed to the high number of generalists and also to the high number of weeds. We found that in the case of specialists, kurgans represented a similarly high phylogenetic diversity to that of continuous grasslands due to the presence of phylogenetically distinct specialist species and species groups. This suggests that both kurgans and continuous grasslands have been able to preserve a considerable amount of evolutionary history across the specialist species, and hence should be the focus of conservation (Barak et al. 2017). The low cPD values of specialists in verges are due to the low species richness of specialists. In verges the species pool was likely filtered by the special habitat characteristics, to which only a narrow group of species (likely with the same evolutionary history) could adapt.

The high phylogenetic diversity of specialists represented by the branch lengths in the continuous grasslands is due to the maintenance of the original species pool preserving the original community structure, whilst in case of kurgans it is likely the outcome of the high level of environmental heterogeneity that supports the co-existence of several specialist species with different evolutionary histories (Kassen 2002). The increased taxonomic and phylogenetic diversity of specialists on kurgans provides flexibility under changing environmental conditions, such as climate fluctuations or small-scale disturbances (Szabó et al. 2019). High diversity of species and the presence of adaptation abilities coded on the gene level provide a higher chance for an adaptive community-level response both for local and larger scale habitat changes. In a taxonomically and phylogenetically more diverse community, there is a higher chance that at least some of the species can survive in a changing environment (Bátori et al. 2019). The low cPD scores for specialist species in verges may be attributed to the high level of disturbance. As previous studies have shown, both secondary origin and disturbance by frequent mowing can considerably decrease the phylogenetic diversity in grasslands (Barak et al. 2017; Turley and Brudvig 2016). Due to dispersal constrains and the presence of abiotic filters, secondary origin can mitigate the immigration of specialist species that otherwise could inhabit the grassland fragment. The increased frequency of mowing can decrease the level of competition, and may result in the selection of close-relative disturbance-tolerant taxa (Grime 1979; Helmus et al. 2010).

High AED values of specialists on kurgans and in continuous grasslands suggest that abundances of specialists are phylogenetically more clustered in these habitats, meaning that species belonging to fewer numbers of clades dominate in these habitats compared to verges. Thus, abundances of indicator specialists are not evenly distributed across the phylogenetic tree. Linking AED to IndVal scores further clarifies this pattern: most of the indicator species representing an evolutionarily unique set of the given community's specialists were present on kurgans (11) and in continuous grasslands (8); their number was lower in verges (6) (Fig. 5). The phylogenetic imbalance observed in continuous grasslands and on kurgans might be attributed to the special habitat conditions to which specialists are adapted. In the case of the continuous grasslands, specialists are especially clustered towards the Lamiaceae family reflecting the long-term moderate level of grazing applied in these habitats. In case of the kurgans, specialists are represented by the tussockforming species of Poaceae, which are adapted to dry kurgan microhabitats. Specialists belonging to the Asteraceae family and to the clade consisting of the Lamiaceae and Scrophulariaceae families represent a species pool adapted to dry, but relatively nutrient rich microhabitats, and can tolerate the effects of abandonment typical of kurgan habitats. We did not observe such clustering in the case of verges, which might be due to their relatively young age and the high level of disturbance. These circumstances allowed a smaller portion of the historical species pool of specialists to occur in verges, and also, due 
to the frequent and often stochastic disturbances evolutionary adaptations are mostly related to re-colonisation (i.e. good dispersal ability) and toleration of disturbance.

\section{Conclusions}

We revealed that both patch-like (kurgans) and linear (verges) grassland fragments have a considerable role in maintaining populations of grassland specialist plant species in transformed landscapes. Kurgans and verges conserve different segments of the species pool due to the differences in their origin, shape, size, applied management regimes and level of habitat heterogeneity. Our results also suggest that for prioritizing the protection of specialists in transformed landscapes, it is essential to focus conservation efforts not only on remnant continuous grassland stands, but also on grassland fragments, as by their protection additional components of diversity can be preserved. Despite their small area, kurgans have the potential to preserve a high species richness of specialists. The main reason for this is that kurgans are characterised by high environmental heterogeneity and provide various microhabitats for species with different habitat demands. Therefore, their protection can offer a cost-effective way of improving the landscape-scale diversity of grassland species in transformed lowland landscapes. We also highlighted that encroachment of weeds poses a serious threat to grassland fragments. Thus, targeted management efforts are needed for the long-term maintenance of these fragile habitats and their vulnerable species. It would be essential to introduce a continuous biomass removal and the suppression of weedy species on abandoned kurgans by annual hand mowing, and if necessary, by brush cutting. In verges, the reduction of management intensity would be favourable in order to decrease the level of disturbance caused by too frequent mowing. In this habitat type mowing would be favourable once or twice per year. This option would be optimal for keeping the well-kept appearance of the verges and to hinder woody encroachment, but would also allow disturbance-sensitive grassland species to establish and reproduce in these habitats.

Author contributions BD and OV contributed to the study conception and design. Data preparation and data collection were performed by BD, OV, KL, AK, RK, ZB, and PJK. Data analyses were performed by ZR. The first draft of the manuscript was written by $\mathrm{BD}$ and $\mathrm{OV}$ and all authors commented on previous versions of the manuscript. All authors read and approved the final manuscript.

Funding Open access funding provided by ELKH Centre for Ecological Research. The study was supported by the NKFI KH 130338, NKFI FK 135329 and NKFI FK 124404 grants. OV, AK and BD were supported by the Bolyai János Scholarship of the Hungarian Academy of Sciences. ZB was supported by the NKFI K 124796 grant.

Data availability All primary data generated during the current study will be made available in a public data repository upon the acceptance of the paper.

\section{Compliance with ethical standards}

Conflict of interest The authors declare that they have no conflict of interest.

Open Access This article is licensed under a Creative Commons Attribution 4.0 International License, which permits use, sharing, adaptation, distribution and reproduction in any medium or format, as long as you give appropriate credit to the original author(s) and the source, provide a link to the Creative Commons licence, and indicate if changes were made. The images or other third party material in this article are included in the 
article's Creative Commons licence, unless indicated otherwise in a credit line to the material. If material is not included in the article's Creative Commons licence and your intended use is not permitted by statutory regulation or exceeds the permitted use, you will need to obtain permission directly from the copyright holder. To view a copy of this licence, visit http://creativecommons.org/licenses/by/4.0/.

\section{References}

Auffret AG, Cousins SAO (2013) Humans as long-distance dispersers of rural plant communities. PLoS ONE 8:e62763

Báldi A (2008) Habitat heterogeneity overrides the species-area relationship. J Biogeogr 35:675-681

Barak R, Williams EW, Hipp AL, Bowles ML, Carr GM, Sherman R, Larkin DJ (2017) Restored tallgrass prairies have reduced phylogenetic diversity compared with remnants. J Appl Ecol 54:1080-1090

Bates D, Maechler M, Bolker B, Walker S (2015) Fitting linear mixed-effects models using lme4. J Stat Softw 67:1-48

Bátori Z, Körmöczi L, Zalatnai M, Erdős L, Ódor P, Tölgyesi C, Margóczi K, Torma A, Gallé R, Cseh V, Török P (2016) River dikes in agricultural landscapes: the importance of secondary habitats in maintaining landscape-scale diversity. Wetlands 36:251-264

Bátori Z, Vojtkó A, Farkas T, Szabó A, Havadtői K, Vojtkó A, Tölgyesi C, Cseh V, Erdős L, Maák I, Keppel G (2017) Large- and small-scale environmental factors drive distributions of cool-adapted plants in karstic microrefugia. Ann Bot 119:301-309

Bátori Z, Vojtkó A, Maák IE et al (2019) Karst dolines provide diverse microhabitats for different functional groups in multiple phyla. Sci Rep 9:7176

Bátori Z, Kiss PJ, Tölgyesi C et al (2020) River embankments mitigate the loss of grassland biodiversity in agricultural landscapes. River Res Appl 36:1160-1170

Bhagwat SA, Rutte C (2006) Sacred groves: potential for biodiversity management. Front Ecol Environ 4:519-524

Biró M, Bölöni J, Molnár Z (2018) Use of long-term data to evaluate loss and endangerment status of Natura 2000 habitats and effects of protected areas. Conserv Biol 3:660-671

Borhidi A (1995) Social behaviour types, the naturalness and relative ecological indicator values of the higher plants in the Hungarian Flora. Acta Bot Hung 39:97-181

Cáceres MD, Legendre P (2009) Associations between species and groups of sites: indices and statistical inference. Ecology 90:3566-3574

Cáceres MD, Legendre P, Moretti M (2010) Improving indicator species analysis by combining groups of sites. Oikos 119:1674-1684

Cadotte MW, Davies TJ, Regetz J, Kembel SW, Cleland E, Oakley TH (2010) Phylogenetic diversity metrics for ecological communities: integrating species richness, abundance and evolutionary history. Ecol Lett 13:96-105

Chiarucci A, Viciani D, Winter C, Diekmann M (2006) Effects of productivity on species-area curves in herbaceous vegetation: evidence from experimental and observational data. Oikos 115:475-483

Council Directive 92/43/EEC of 21 May 1992 on the conservation of natural habitats and of wild fauna and flora

Cousins SAO (2006) Plant species richness in midfield islets and road verges - the effect of landscape fragmentation. Biol Conserv 127:500-509

Deák B, Tóthmérész B, Valkó O et al (2016) Cultural monuments and nature conservation: the role of kurgans in maintaining steppe vegetation. Biodivers Conserv 25:2473-2490

Deák B, Valkó O, Török P, Kelemen A, Bede Á, Csathó ÁI, Tóthmérész B (2018) Landscape and habitat and filters jointly drive richness and abundance of grassland specialist plants in terrestrial habitat islands. Lands Ecol 33:1117-1132

Deák B, Valkó O, Nagy DD et al (2020) Habitat islands outside nature reserves-threatened biodiversity hotspots of grassland specialist plant and arthropod species. Biol Conserv 241:108254

Dembicz I, Szczeparska L, Moysiyenko II, Wódkiewicz M (2018) High genetic diversity in fragmented Iris pumila L. populations in Ukrainian steppe enclaves. Basic Appl Ecol 28:37-47

Dengler J, Matthews TJ, Steinbauer MJ et al (2020) Species-area relationships in continuous vegetation: evidence from Palaearctic grasslands. J Biogeogr 47:72-86

Devictor V, Mouillot D, Meynard C, Jiguet F, Thuiller W, Mouquet N (2010) Spatial mismatch and congruence between taxonomic, phylogenetic and functional diversity: the need for integrative conservation strategies in a changing world. Ecol Lett 13:1030-1040 
Dupre C, Diekmann M (2001) Differences in species richness and life-history traits between grazed and abandoned grasslands in southern Sweden. Ecography 24:275-286

Durka W, Michalski GS (2012) Daphne: a dated phylogeny of a large European flora for phylogenetically informed ecological analyses. Ecology 93:2297

Fekete R, Mesterházy A, Valkó O, Molnár VA (2018) A hitchhiker from the beach—the spread of a maritime, halophyte species (Cochlearia danica L.) along salted continental roads. Preslia 90:23-37

Fick SE, Hijmans RJ (2017) Worldclim 2: new 1-km spatial resolution climate surfaces for global land areas. Int J Climatology 37:4302-4315

Filibeck G, Sperandii MG, Bazzichetto M, Mancini LD, Rossini F, Cancellieri L (2019) Exploring the drivers of vascular plant richness at very fine spatial scale in sub-mediterranean limestone grasslands (Central Apennines, Italy). Biodivers Conserv 28:2701-2725

Fletcher RJ, Didham RK, Banks-Leite C et al (2018) Is habitat fragmentation good for biodiversity? Biol Conserv 226:9-15

Godó L, Tóthmérész B, Valkó O et al (2018) Ecosystem engineering by foxes is mediated by isolation in grassland fragments. Ecol Evol 8:7044-7054

Grime JP (1979) Plant strategies and vegetation processes. Wiley, Chichester, New York, Brisbane, Toronto

Helmus MR, Keller W, Paterson MJ, Yan ND, Cannon CH, Rusak JA (2010) Communities contain closely related species during ecosystem disturbance. Ecol Lett 13:162-174

Kassen R (2002) The experimental evolution of specialists, generalists, and the maintenance of diversity. J Evol Biol 15(2):173-190

Krijthe JH (2015) Rtsne: T-distributed stochastic neighbor embedding using a Barnes-Hut implementation (Version 0.15) [Computer software]. https://github.com/jkrijthe/Rtsne

Kuussaari M, Bommarco R, Heikkinen RK et al (2009) Extinction debt: a challenge for biodiversity conservation. Trends Ecol Evol 24:564-571

Kuznetsova A, Brockhoff PB, Christensen RHB (2017) lmerTest Package: tests in linear mixed effects models. J Stat Softw. https://doi.org/10.18637/jss.v082.i13

Lenth R (2019) emmeans: estimated marginal means, aka least-squares means (Version 1.3.4) [R]. https:// CRAN.R-project.org/package $=$ emmeans

Lindborg R, Plue J, Andersson K, Cousins SAO (2014) Function of small habitat elements for enhancing plant diversity in different agricultural landscapes. Biol Conserv 169:206-213

Lisetskii FN, Sudnik-Wójcikowska B, Moysiyenko II (2016) Flora differentiation among local ecotypes in the transzonal study of forest-steppe and steppe mounds. Biol Bull 43:169-176

Löki V, Molnár VA, Süveges K et al (2019) Predictors of conservation value of Turkish cemeteries: a case study using orchids. Landsc Urban Plan 186:36-44

MacArthur RH, Wilson EO (1967) The theory of island biogeography. Princeton University Press, Princeton

Molnár VA, Nagy T, Löki V, Süveges K, Takács A, Bódis J, Tökölyi J (2017) Graveyards as refuges for Turkish orchids against salep harvesting. Ecol Evol 23:11257-11264

Oksanen J, Blanchet FG, Friendly M et al. (2019) vegan: Community ecology package (Version 2.5-5) [Computer software]. https://CRAN.R-project.org/package=vegan

Polyakova MA, Dembicz I, Becker T et al (2016) Scale- and taxon-dependent patterns of plant diversity in steppes of Khakassia, 684 South Siberia (Russia). Biodivers Conserv 25:2251-2273

Qian H, Jin Y (2016) An updated megaphylogeny of plants, a tool for generating plant phylogenies and an analysis of phylogenetic community structure. J Plant Ecol 9:233-239

R Core Team (2019) R: a language and environment for statistical computing. R Foundation for Statistical Computing, Vienna

Rosenthal G, Lederbogen D (2008) Response of the clonal plant Apium repens (Jacq.) Lag. to extensive grazing. Flora 203(2):141-151

Steemans P, Le Hérissé A, Melvin J, Miller MA, Paris F, Verniers J, Wellman CH (2009) Origin and radiation of the earliest vascular land plants. Science 324(5925):353-353

Stein A, Gerstner K, Kreft H (2014) Environmental heterogeneity as a universal driver of species richness across taxa, biomes and spatial scales. Ecol Lett 17:866-880

Suárez-Esteban A, Delibes M, Fedriani JM (2013) Unpaved road verges as hotspots of fleshy-fruited shrub recruitment and establishment. Biol Conserv 167:50-56

Sudnik-Wójcikowska B, Moysiyenko I, Zachwatowicz M (2011) The value and need for protection of kurgan flora in the anthropogenic landscape of steppe zone in Ukraine. Plant Biosyst 145:638-653

Szabó S, Elemér L, Kovács Z, Püspöki Z, Kertész Á, Singh SK, Balázs B (2019) NDVI dynamics as reflected in climatic variables: spatial and temporal trends-a case study of Hungary. GIScience Remote Sens 56:624-644

Szava-Kovats R, Zobel M, Pärtel M (2012) The local-regional species richness relationship: new perspectives on the null-hypothesis. Oikos 121:321-326 
Tikka PM, Koski PS, Kivelä RA, Kuitunen MT (2000) Can grassland plant communities be preserved on road and railway verges? Appl Veg Sci 3:25-32

Tucker CM, Cadotte MW, Carvalho SB et al (2017) A guide to phylogenetic metrics for conservation, community ecology and macroecology. Biol Rev 92:698-715

Turley NE, Brudvig LA (2016) Agricultural land-use history causes persistent loss of plant phylogenetic diversity. Ecology 97:2240-2247

Valkó O, Lukács K, Deák B et al (2020) Laundry washing increases dispersal efficiency of cloth-dispersed propagules. NeoBiota 60:1-16

van der Maaten L (2014) Accelerating t-SNE using tree-based algorithms. J Mach Learn Res 15:3221-3245

van der Ree R, Smith DJ, Grilo C (2015) Handbook of road ecology. Wiley-Blackwell, Oxford

Publisher's Note Springer Nature remains neutral with regard to jurisdictional claims in published maps and institutional affiliations.

\section{Affiliations}

\section{Balázs Deák ${ }^{1}$ (D) $\cdot$ Zoltán Rádai $^{1}$ (D) Katalin Lukács ${ }^{1} \cdot$ András Kelemen $^{1}$ (D) Réka Kiss ${ }^{1}$ (D) Zoltán Bátori ${ }^{2}$ (D) $\cdot$ Péter János Kiss $^{2} \cdot$ Orsolya Valkó $^{1}$}

$\triangle$ Balázs Deák

debalazs@gmail.com

1 Lendület Seed Ecology Research Group, Institute of Ecology and Botany, Centre for Ecological Research, Alkotmány út 2-4, Vácrátót 2163, Hungary

2 Department of Ecology, University of Szeged, Közép fasor 52, Szeged 6726, Hungary 